\title{
A Method for Prevention of Spread of Novel Coronavirus (COVID-19) in a Dental Clinic
}

\author{
Gejo Johns ${ }^{1}$, Evelyn Sara George ${ }^{2}$
}

\begin{abstract}
Aim: The aim of this study is to give the clinician information related to the prevention of cross-infections in the dental clinic. In a dental office setup, there are high chances of clinician and other noninfected patients to get contaminated by saliva mixed with blood, pus, plaque, and crevicular fluid is often aerosolized and spattered, thus exposing the dental professional to potentially infectious agents mainly the novel coronavirus 2019. Prevention should be made mandatory because microorganisms are always mixed with these body materials and they cause infectious and transmissible disease. In this circumstance, it becomes mandatory for the dental professional to follow the universal precautions and treat every patient safely.

Conclusion: The dentist must hence be aware of these precautions and should mandatorily follow the infection control protocol in his dental setup. Keywords: Coronavirus, Hand wash, Sterilization, Universal prevention, Waste disposal.

Journal of Oral Health and Community Dentistry (2021): 10.5005/jp-journals-10062-0095
\end{abstract}

\section{INTRODUCTION}

The novel coronavirus 2019 (COVID-19) was caused by SARS-CoV 2 a positive-sense single-stranded RNA virus from the family coronaviridae. COVID-19 outbreak of respiratory illness caused by the novel (new) coronavirus that was initially reported in Wuhan City, Hubei Province, China and which continues to spread and expand. On January 30, 2020, the International Health Regulations Emergency Committee of the World Health Organization (WHO) declared the outbreak and has been designed as a pandemic and Public health emergency of international concern.

Considering the rate and potential of spread of this disease among public health workers including the dental professionals and the dentist should be cautious enough not to become a potential carrier and protect the working area or the dental office from being a source of this disease which may lead to nosocomial infection. During the routine dental procedures to our patients, the amount of aerosol generated and the handling of sharp instruments can be a potential source of cross infection and make us the high-risk group prone to the virus attack.

\section{Transmission of Novel Coronavirus}

The virus is more likely to spread from person-to-person during close contacts (about $6 \mathrm{ft}$ ). The infection gets transmitted mainly via respiratory droplets that are generated from the infected person during coughing or sneezing, similar to how other respiratory diseases are spread like influenza. Droplets that are released from the infected person will be inhaled into the lungs or get landed in the mouths or noses of a noninfected person who is nearby or in close contact with the infected individual. And it is unclear that how a noninfected person can get COVID-19 by touching a surface or object that has the virus on it and by touching their own mouth, nose, or possibly their eye. The virus tends to bind the normal cell and hijack the cell and turns it into a virus factory. Wrapp et al. ${ }^{1}$ identified that COVID-19 makes use of a densely glycosylated spike protein a trimeric class I fusion protein that undergoes a substantial structural rearrangement to fuse to the cell membrane (Fig. 1).
${ }^{1}$ Department of Orthodontics and Dentofacial Orthopedics, Annoor Dental College and Hospitals, Muvattupuzha, Kerala, India

${ }^{2}$ Private Practitioner, Kerala, India

Corresponding Author: Gejo Johns, Department of Orthodontics and Dentofacial Orthopedics, Annoor Dental College and Hospitals, Muvattupuzha, Kerala, India, Phone: +91 9945608547, e-mail: gejoissacjohns@gmail.com

How to cite this article: Johns G, George ES. A Method for Prevention of Spread of Novel Coronavirus (COVID-19) in a Dental Clinic. J Oral Health Comm Dent 2021;15(1):16-19.

Source of support: Nil

Conflict of interest: None

\section{Symptoms of COVID-19}

Guan et al. ${ }^{3}$ conducted a study and found that the incubation period for this disease is 4 days. The symptoms include fever $88.7 \%$, cough $67.8 \%$, nausea and vomiting $5 \%$, and diarrhea $3.8 \%$. The median time from the onset of disease to dyspnea is 8 days.

\section{Diagnosis}

The diagnosis of COVID-19 is as given in the flowchart (Fig. 2).

\section{Preventive Measures in Dental Clinic}

During the oral examination, the patient is asked to rinse the mouth with an antimicrobial mouth rinse to reduce the microbial load in the oral cavity (Kohn et al. ${ }^{4}$; Marui et al. ${ }^{5}$ ). The dental procedures that are more likely to induce the chances of coughing should be performed cautiously or avoided (WHO 2020a). The use of a 3-way syringe and airotor handpiece that generates aerosol should be avoided or minimized as much as possible. If it is necessary to perform these procedures with a handpiece and 3-way syringe, the healthcare providers in the room should wear a personal protective kit which includes N95 masks, eye protection, gloves, and gowns compulsory. Air from this room should be exhausted directly to the high-efficiency particulate air filter before recirculation. 


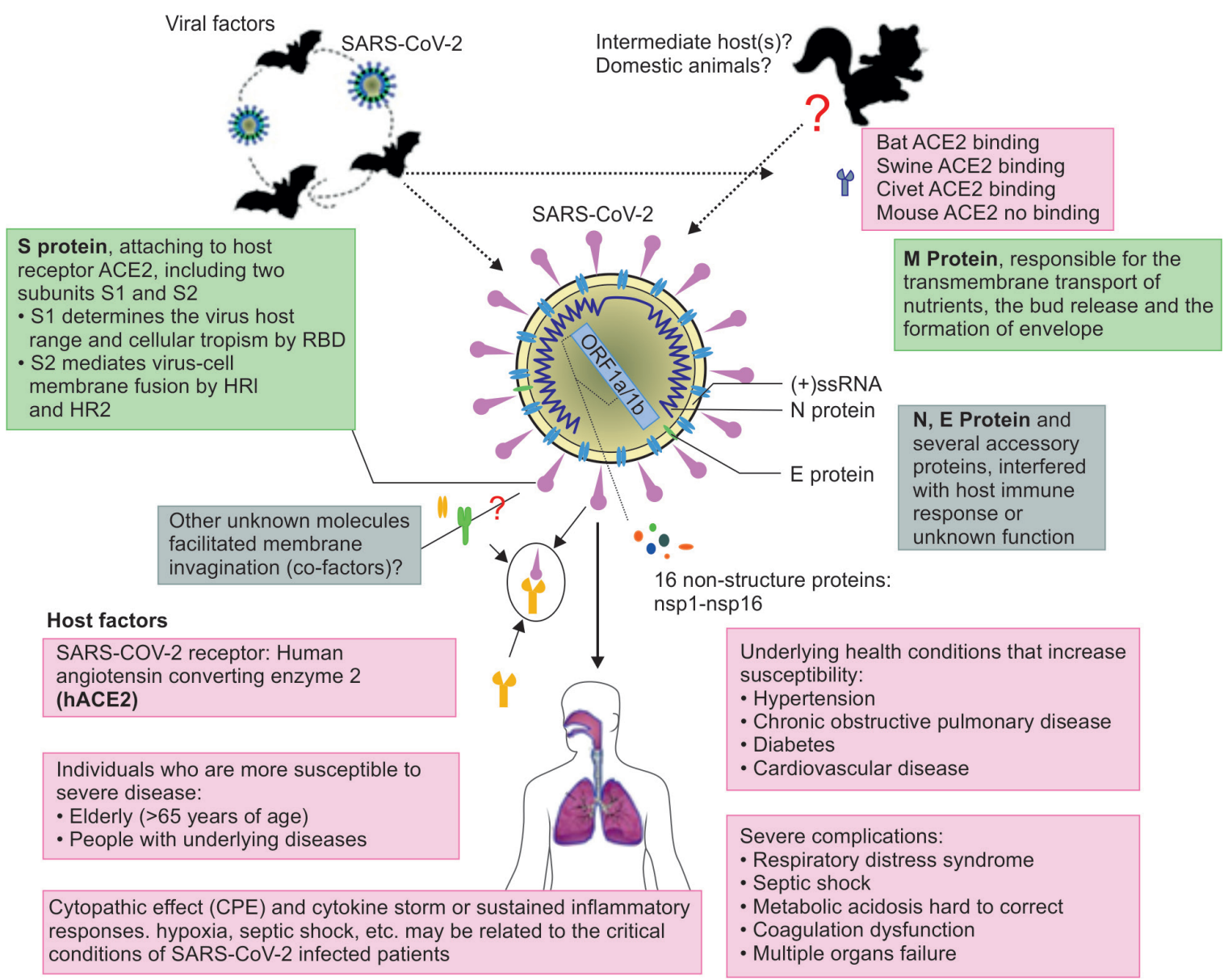

Fig. 1: Virus and host factors influencing pathogenesis (adapted from Guo et al. ${ }^{2}$ )

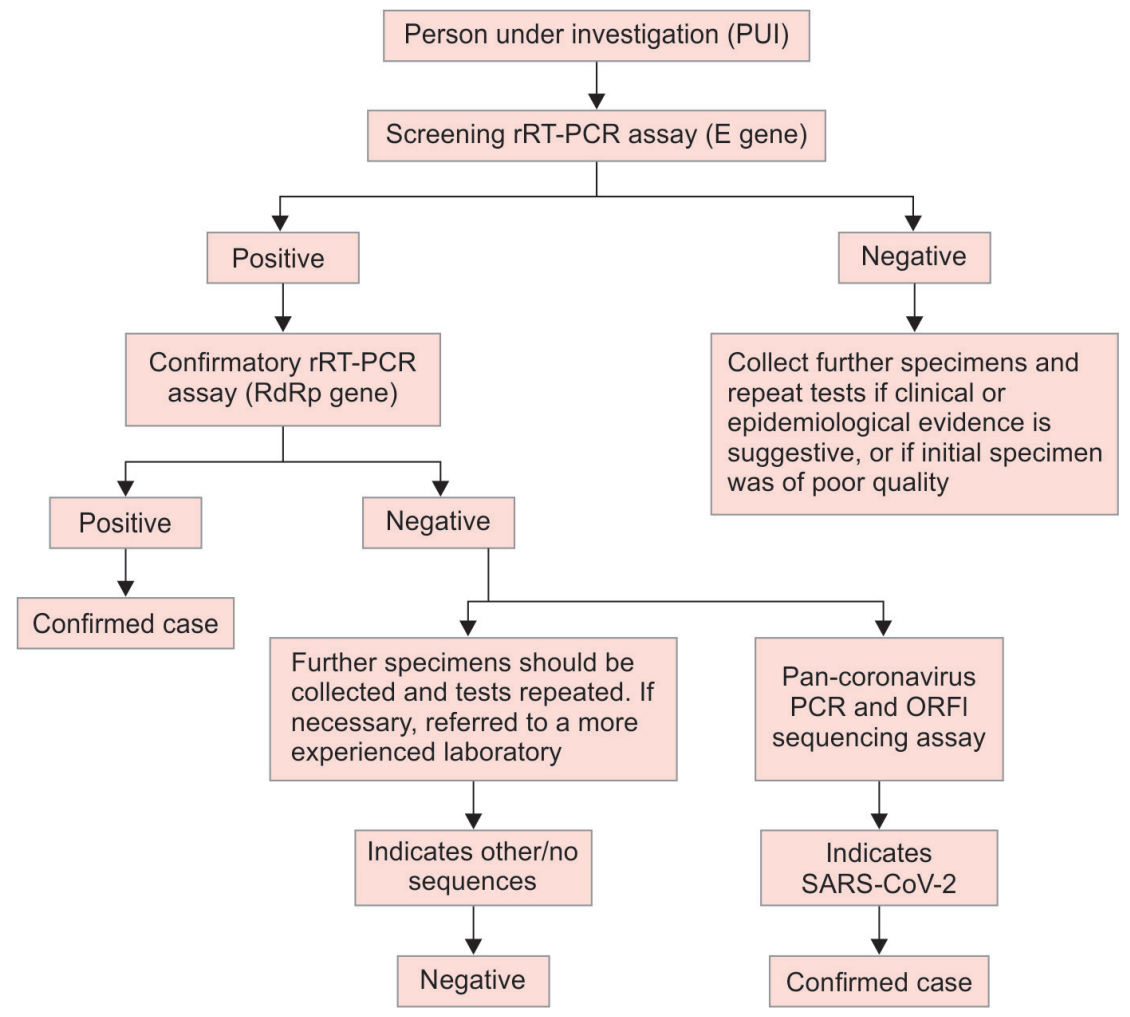

Fig. 2: Laboratory procedure following the specimen collection 
According to Vandenberghe et al. ${ }^{6}$ intraoral x-ray radiographic technique which is commonly using in dental imaging can stimulate saliva secretion and coughing. Therefore, it is advisable to perform extraoral dental radiographic techniques such as the use of panoramic radiography and cone-beam computed tomography which are appropriate and are safe alternatives during the outbreak of COVID-19.

During the treatment of dental emergency cases to minimize the release of aerosol or spatter, it is advised to use rubber dams ${ }^{7}$ and high-volume saliva ejectors.

\section{Personal Protective Equipment (PPE)}

PPE is equipment or specialized clothing worn by a healthcare worker for protection against a hazard. PPE should be in accordance with the OSHA regulations which are as follows:

- CATEGORY 1-Involve exposure to blood, body fluids, or tissues. The employees in this category are instructed to use appropriate protective measures, e.g., dentist, dental assistant, dental hygienist, lab technician.

- CATEGORY 2-Involve no exposure to blood, body fluids, or tissues; however, unplanned category 1 tasks may occasionally be required. The employees in this category should be provided with appropriate protective measures readily available, e.g., workers who may help clean up the office, handle instruments or impression materials, or send dental materials to the laboratory.

- CATEGORY 3-Involve no exposure to blood, body fluids, or tissues, e.g., receptionist.

\section{Sterilization}

Common methods that are employed in office sterilization in dentistry include:

- Autoclaving: Long cycle- $121^{\circ} \mathrm{C}$ for 15 minutes at 15 psi, short cycle $-134^{\circ} \mathrm{C}$ for 3 minutes at 30 psi.

- Instruments sterilized are stainless steel instruments, handpieces, cloth goods, glass slabs, dishes, plastic suction tips.

- Chemiclaves: It consists of the use of a combination of liquid chemicals (with $<15 \%$ water). The parameters for sterilizing are $131^{\circ} \mathrm{C}$ for 30 minutes at $20 \mathrm{psi}$

- Instruments sterilized are hand instruments, handpieces, carbon and diamond burs, orthodontic wires, endodontic instruments.

- Hot air oven 160 to $170^{\circ} \mathrm{C}$ for 1 -hour instruments disinfection.

- Instruments and operatory surfaces can be classified as

o Critical: Instruments that penetrate tissue or touch bone, e.g., scissors, forceps, elevator, scaler. These must be autoclaved.

o Semicritical: Instruments that touch mucous membrane but do not penetrate, e.g., mouth mirror probes, tweezers, amalgam carrier. Can be either autoclaved or subjected to high-level disinfection

o Noncritical: Instruments that contact only intact skin, e.g., spatula, mixing slab, and protective eyewear. These should be subjected to intermediate-level disinfection.

Surfaces to be barriered: This includes light handles of electrical or mechanical controls of the dental unit, and headrest and armrest unit controls of the dental chair. High-speed handpiece couplings and hose, slow speed motor, coupling, and hose. Air/water syringe saliva ejectors, handpiece, and hose. X-ray unit handles and cone bite blocks of the panoramic X-ray unit intraoral digital sensors Radiovisiography equipment .
Table 1: Waste category treatment and disposal

\begin{tabular}{lll}
\hline Category & Waste & Disposal methods \\
\hline Category 1 & Generated human & Incineration/deep burial \\
& $\begin{array}{l}\text { anatomical waste } \\
\text { (human tissues, organs, } \\
\text { body parts) }\end{array}$
\end{tabular}

Category 2 Generated animal waste Incineration/deep burial (animal tissues, organs, body parts carcasses, bleeding parts, fluids, blood)

Category 3 Generated microbiology Incineration/deep burial and biotechnology waste (waste from lab cultures, research and infectious agents from research and industrial lab)

Category 4 Sharps (needles, syringes, Incineration/disinfection scalpel, blades, glass) treatment/mutilation

Category 5 Medicines and cytotoxic Incineration/destruction drugs

Category 6 Solid waste (blood and Autoclave/chemical body fluids)

Category 7 Solid waste (disposable items

Category 8 Generated liquid waste (waste generated from lab, and washing, cleaning, housekeeping, and disinfecting activities)

Category 9 Incineration ash Disposal in municipal landfill

Category 10 Chemical waste Chemical treatment/ secure landfill

\section{Dispose of Contaminated Waste Safely}

Clinical wastes that are generated in the dental clinic which includes blood-soaked gauges, cotton rolls, extracted teeth, tissue waste, and contaminated sharps such as needles, surgical blades, etc., should be placed in a leak-proof containers or bags that are colorcoded or labeled. These containers or bags are tightly sealed and disposed safely as mentioned in (Table 1) to prevent leakage during handling, storage, and transport.

\section{Color Coding and Type of Container}

YELLOW (plastic bag) Categories 1, 2, 3, and 6

RED (disinfected container/plastic bag) Categories 3, 6, and 7

BLUE/WHITE (plastic bag, puncture-proof container) Categories 4 and 7

\section{BLACK (plastic bag) Categories 5, 9, and 10 (Table 1)}

\section{Infection Control Program for Dental Assistant}

The staff must be trained based on following OSHA regulations.

This includes the proper use of universal protection procedures which include PPE, the meaning of color-coding, biohazard symbol, precautions to follow in handling contaminated articles or infectious waste and action required, and who to contact if unplanned and proper work practices and their limitations. 


\section{Discussion}

Due to the rampant increase in the spread of SARS-CoV-2 as a pandemic increases the likelihood and risk for the dental healthcare professionals who treat this subset of the patient population. To minimize the spread of the virus and its associated diseases, universal precautionary measures are crucial. As further precautions, careful prescreening of patients and additional measures are necessary if treatment of patients with confirmed COVID-19 is deemed necessary.

\section{Conclusion}

Dentists as healthcare professionals have the duty to protect the general and public population and maintaining a high standard of proper infection control and care. This new emerging pandemic SARS-CoV-2 threatens the worldwide population and can become a more common communicable infection and less pathogenic, and it is predicted to persist in the population as a less virulent infection with milder symptoms, if it follows the same evolutionary pattern of the other coronavirus infections (i.e., SARS-CoV and MERS-CoV). Thus, it is important to make informed clinical decisions and be aware and help in educating the general population to prevent panic in these circumstances and while promoting their health and well-being of the patients during these challenging situations.

\section{References}

1. Wrapp D, Wang N, Corbett KS, et al. Cryo-EM structure of the 2019-nCoV spike in the prefusion conformation. Science 2020;367(6483):1260-1263. DOI: 10.1126/science.abb2507.

2. Guo YR, Cao QD, Hong ZS, et al. The origin, transmission and clinical therapies on coronavirus disease 2019 (COVID-19) outbreak-an update on the status. Mil Med Res 2020;7(1):11. DOI: 10.1186/s40779020-00240-0.

3. Guan WJ, Ni ZY, Hu Y, et al. Clinical characteristics of coronavirus disease 2019 in China. N Engl J Med 2020;382:1708-1720. DOI: 10.1056/ NEJMoa2002032.

4. Kohn WG, Collins AS, Cleveland JL, et al. Guidelines for infection control in dental health-care settings-2003. 2003;52(RR17):1-61 .

5. Marui VC, Souto ML, Rovai ES, et al. Efficacy of preprocedural mouthrinses in the reduction of microorganisms in aerosol: a systematic review. J Am Dent Assoc 2019;150(12):1015-1026. DOI: 10.1016/j.adaj.2019.06.024.

6. Vandenberghe B, Jacobs R, Bosmans H. Modern dental imaging: a review of the current technology and clinical applications in dental practice. Eur Radiol 2010;20(11):2637-2655. DOI: 10.1007/s00330-0101836-1.

7. Samaranayake L, Reid J, Evans D. The efficacy of rubber dam isolation in reducing atmospheric bacterial contamination. ASDC J Dent Child 1989;56(6):442-444. 